\title{
Comparison of QSOFA score and SIRS criteria for prediction of sepsis outcome of patients with suspicion of sepsis outside the intensive care unit: A single-center retrospective study
}

\author{
Maryamsadat Mosavi \\ Guilan University of Medical Sciences \\ lida Mahfoozi ( $\square$ Imahfoozi99@gmail.com) \\ Guilan University of Medical Sciences
}

Research note

Keywords: Sepsis, SIRS, qSOFA, Emergency

Posted Date: March 4th, 2021

DOI: https://doi.org/10.21203/rs.3.rs-286120/v1

License: (c) (1) This work is licensed under a Creative Commons Attribution 4.0 International License. Read Full License 


\section{Abstract}

\section{Objective:}

The present study aimed to determine quick Sepsis-related Organ Failure Assessment (qSOFA) in comparison with systemic inflammatory response syndrome (SIRS) in the prediction of the adverse consequences for the suspected sepsis patients outside the ICU.

\section{Results:}

Out of 128 patients with suspected sepsis, $87(68 \%)$ patients were confirmed to have septicemia based on SIRS criteria. The SIRS criteria classified $68 \%$ patients as sepsis $(87 / 128)$, of which $39(44.8 \%)$ had positive qSOFA score. The sensitivity and specificity ratios of qSOFA were $44.83 \%$ and $80.49 \%$, respectively.

ROC curve analysis showed that the area under ROC curve (AUC) of the pSOFA score for predicting the prognosis of sepsis patients were not significantly different. Moreover, regarding the sepsis-related mortality, the area under ROC showed that the qSOFA criteria (score $\geq 2$ ) is suitable for predicting mortality with a sensitivity of $71 \%$ and specificity of $72 \%$.

Our findings revealed that the qSOFA score was significantly efficient in predicting mortality. However, the SIRS is more sensitive than the qSOFA score in predicting of the definite diagnosis of sepsis. Therefore, the qSOFA score may seem to be an invaluable tool for the identification of sepsis patients at the emergency department.

\section{Introduction:}

Sepsis is a critical condition that causes $10 \%$ of intensive care unit (ICU) cases and 10 to $20 \%$ of inhospital mortality rates worldwide $(1-3)$. In the last few decades, the incidence of sepsis and severe sepsis has increased probably due to the fact that they are easier to diagnose among the aging patients $(4,5)$.

That the rapid detection of sepsis can lead to its early intervention attracted much attention in the emergency department (ED). The former consensus explanations of sepsis needed the criteria for the infection and two or more systemic inflammatory response syndrome (SIRS) [6, 7]. Tachypnea (respiratory rate of over 20 breaths per minute), leukopenia or leukocytosis (leucocyte count of higher than 12,000 cells $/ \mu \mathrm{L}$ or $<4000 / \mu \mathrm{L}$ ), tachycardia (heart rate of over ninety beats per minutes), and hypothermia or fever (body temperature of less than $36^{\circ} \mathrm{C}$ or higher than $38^{\circ} \mathrm{C}$, respectively) are four SIRS criteria(6). Nevertheless, SIRS was criticized for its prognostic value, utility, and inadequately specificity(6).

Currently, an international task force in the third international consensus explanations redefined this Loading [MathJax]/jax/output/CommonHTML/jax.js psis (7). Accordingly, sepsis is considered a life-threatening 
organ dysfunction resulted from a reaction of the dysregulated host to the infection. The acute increase of at least two points in the Sequential Organ Failure Assessment (SOFA) score characterized organ dysfunction (5).

Using the quick Sepsis-related Organ Failure Assessment (qSOFA) was also redefined in the recent Sepsis-3 guidelines. The studies indicated that qSOFA was more accurate than the SIRS score in predicting the death outside the ICU(8). In SEPSIS-3, qSOFA criteria are recommended outside the ICU to encourage the clinicians in assessing the organ dysfunction further and initiate a therapy appropriately (9).

Novel criteria in the qSOFA were represented in sepsis-3 (The qSOFA scores within the ranges of 0-3; each receiving 1 point if meeting the following criteria: altered mental status, respiratory rate $>21$ breaths/min, and systolic blood pressure of less than or equal to $100 \mathrm{mmHg})(10)$.

The long ICU stay and higher mortality risk are caused by qSOFA $\geq 2(11)$. The explanation group indicated qSOFA as a better predictor of mortality compared to SIRS, suggesting the use of qSOFA score of 2 or higher rather than a SIRS score to identify the infected patients with a higher risk of death (12). Early diagnosis and treatment of sepsis is necessary to decrease the morbidity, mortality, and hospital stay length. The novel explanation can improve the study on treating patients with more critical sepsis. Hence, the present study aimed to determine the effect of qSOFA in comparison with SIRS in the prediction of the adverse consequences for the suspected sepsis patients outside the ICU.

\section{Methods:}

\section{Study design and patient population}

This retrospective study was conducted on patients transferred to the emergency medicine department of Razi hospital between March 2018 and March 2019. All the hospitalized patients with a suspected infection who were SIRS positive with positive microbial cultures (Blood, Urine and CSF) or/and received antibiotics within $48 \mathrm{hr}$ of admission on the ED were enrolled in this study. We considered the patients to have sepsis if they had two or more than SIRS criteria. Suspicion of infection was made using the following data extracted from hospital records: blood pressure, heart rate, body temperature, respiratory rate and level of consciousness. The exclusion criteria were the patients who did not have demographic, laboratory variables and SIRS criteria. After final diagnosis, the patients were divided into two groups (the group with and without the final diagnosis of sepsis). Then, we examined the qSOFA criteria in these two groups and compared the number of patients who were diagnosed with sepsis based on the qSOFA and sirs criteria. In addition, SIRS criteria served as the gold standard for the diagnosis of sepsis.

\section{Data extraction protocol}

The demographics, comorbidities, vital signs, site of infection, clinical variables, and laboratory results were recorded on a data collection form designed for the study. All the data were extracted from the Loading [MathJax]/jax/output/CommonHTML/jax.js 
electronic medical record system of the first Affiliated Razi Hospital of Guilan Medical University. In this regard, the vital signs of the patients were used to determine the presence of both SIRS criteria and the qSOFA score.

\section{Results:}

\section{Characteristics of the study subjects}

During one year of study, out of 128 patients with suspected sepsis, 87 (68\%) patients were confirmed to have septicemia based on SIRS criteria. The median age of subjects was $72.8 \pm 15.9$ years; $50.6 \%$ (44/87) of them were male. The mean age of both sexes was not significantly different. Table 1 shows the baseline characteristics and clinical outcomes of the patients. 
Table 1

The baseline characteristics and clinical outcomes of the patients.

\begin{tabular}{|lll|}
\hline Variable & Patients with definitive sepsis & Patients without sepsis \\
\hline Male & $44(50.6)$ & $16(39)$ \\
\hline Female & $43(49.4)$ & $25(61)$ \\
\hline SBP & $115 \pm 21.5$ & $120.4 \pm 22.1$ \\
\hline DBP & $69.6 \pm 10.3$ & $70.6 \pm 10.01$ \\
\hline PR & $91.5 \pm 14.6$ & $86.7 \pm 13.8$ \\
\hline RR & $18.5 \pm 5.01$ & $18.1 \pm 4.5$ \\
\hline T & $38.4 \pm 0.5$ & $38.07 \pm 0.5$ \\
\hline WBC & $15621.8 \pm 4413.3$ & $13963.4 \pm 3138.1$ \\
\hline PT & $12.3 \pm 0.8$ & $12.2 \pm 0.41$ \\
\hline PTT & $29.2 \pm 1.8$ & $28.6 \pm 1.2$ \\
\hline BUN & $29.5 \pm 10.3$ & $26.5 \pm 8.6$ \\
\hline CR & $2.6 \pm 1.07$ & $1.2 \pm 0.37$ \\
\hline Type of infection* & & $13(48.1)$ \\
\hline Pneumonia & $37(46.8)$ & $11(40.7)$ \\
\hline UTI & $21(26.6)$ & 0 \\
\hline Intra-abdominal infection & $7(8.9)$ & $3(11.1)$ \\
\hline SSTIs & $14(17.7)$ & \\
\hline UTI: Urinary tract infection; SSTIs:Skin and soft tissue infections; SBP: ; DBP: diastolic blood pressure; & \\
\hline PR: progesterone-receptor; RR: T; troponin; PT: The prothrombin time; PT : partial thromboplastin \\
\hline * $p=0.23$ & & \\
\hline
\end{tabular}

Accordingly, pneumonia was the most common site of infection ( 46.8 and $48.1 \%$ ) followed by the urinary tract $(26.6$ and $40.7 \%)$ among sepsis and non- sepsis patients, respectively. However, there was no significant relationship between the site of infection and sepsis $(p=0.22)$

The SIRS criteria classified 68\% patients as sepsis (87/128), of which $39(44.8 \%)$ and $48(55.2 \%)$ had positive and negative qSOFA score, respectively. In this regard, there was a significant correlation between the qSOFA score and sepsis. $(p=0.006)$. 
The sensitivity and specificity ratios of qSOFA were $44.83 \%$ (95\% Cl: 34.15 to $55.87 \%$ ) and $80.49 \%$ (95\% Cl: 65.13 to $91.18 \%$ ), respectively. Table 2 summarizes the sensitivity and specificity of the qSOFA index according to the comorbidity disease.

Table 2

The results of qSOFA score for diagnosis of sepsis patients with comorbidity

\begin{tabular}{|c|c|c|c|}
\hline Sepsis and Co-morbidity & & Negative-qSOFA & Positive- qSOFA \\
\hline \multirow[t]{2}{*}{ Sepsis + Hypertension } & Yes & $25(55.6)$ & $31(83.8)$ \\
\hline & No & $20(44.4)$ & $6(16.2)$ \\
\hline \multirow[t]{2}{*}{ Sepsis + Diabetic } & Yes & $27(62.8)$ & $23(88.5)$ \\
\hline & No & $16(37.2)$ & $3(11.5)$ \\
\hline \multirow[t]{2}{*}{ Sepsis + IHD } & Yes & $12(52.2)$ & $27(81.8)$ \\
\hline & No & $11(47.8)$ & $6(18.2)$ \\
\hline \multirow[t]{2}{*}{ Sepsis + COPD } & Yes & $3(50)$ & $2(100)$ \\
\hline & No & $3(50)$ & 0 \\
\hline \multirow[t]{2}{*}{ Sepsis + CVA } & Yes & $4(100)$ & $16(84.2)$ \\
\hline & No & 0 & $3(15 . .8)$ \\
\hline \multirow[t]{2}{*}{ Sepsis + Cirosis } & Yes & 0 & $1(100)$ \\
\hline & No & 0 & 0 \\
\hline \multirow[t]{2}{*}{ Sepsis + Cancer } & Yes & $10(90.9)$ & 0 \\
\hline & No & $1(9.1)$ & $1(100)$ \\
\hline \multirow[t]{2}{*}{ Sepsis + CKD } & Yes & $2(100)$ & $5(83.3)$ \\
\hline & No & 0 & $1(16.7)$ \\
\hline \multicolumn{4}{|c|}{ qSOFA: quick SOFA; IHD: ischemic heart disease, CVA: Cerebrovascular accider } \\
\hline
\end{tabular}

ROC curve analysis showed that the area under ROC curve (AUC) of the qSOFA score for predicting the prognosis of sepsis patients were not significantly different $0.627(p=0 / 021)$ Fig. 1 Sup (A). Moreover, regarding the sepsis-related mortality, the area under ROC showed that the qSOFA criteria (score $\geq 2$ ) is suitable for predicting mortality (AUC, $0.71 ; p<0.001$ ) with a sensitivity of $71 \%$ and specificity of $72 \%$. Figure 1 Sup (B).

Thirty-four (34/87) patients with definitive sepsis died during hospitalization. Out of 34 expired patients, Loading [MathJax]/jax/output/CommonHTML/jax.js 
respectively.

Accordingly, a significant correlation was observed between the mortality in patients with sepsis (SIRS criteria) and qSOFA score results $(p \geq 0.001)$. The results of qSOFA score for diagnosis of sepsis patients with comorbidity are shown in Table 2.

There was statistically-significant correlation between the sepsis patients with hypertension $(p=0.006)$, diabetes $(p=0.027)$, ischemic heart disease (IHD) $(p=0.018)$, and results of qSOFA score. In this regard, no significant correlation was found between the sepsis patients with $\operatorname{COPD}(p=0.46)$, cerebrovascular accident (CVA) $(p=0.98)$ and chronic kidney disease (CKD) $(p=0.98)$ and cancer $(p=0.16)$ and results of qSOFA score. Moreover, the sensitivity of the qSOFA score in the diagnosis of sepsis was $80,69.2,55.3$ and $46 \%$ in CVA, IHD, hypertension, and diabetes patients in SIRS positive sepsis, respectively. The Specificity and sensitivity of the qSOFA index in the diagnosis of sepsis according to the associated disease are presented in Table 3.

Table 3

The Specificity and sensitivity of the qSOFA index in the diagnosis of sepsis according to the comorbidity

\begin{tabular}{|c|c|c|c|c|c|c|}
\hline qSOFA score & $\begin{array}{l}\text { Sensitivity } \\
(95 \% \mathrm{Cl})\end{array}$ & $\begin{array}{l}\text { Specificity } \\
(95 \% \mathrm{Cl})\end{array}$ & $\begin{array}{l}\text { Disease } \\
\text { prevalence }\end{array}$ & $\begin{array}{l}\text { Positive } \\
\text { Predictive } \\
\text { Value (95\% } \\
\text { Cl) }\end{array}$ & $\begin{array}{l}\text { Negative } \\
\text { Predictive } \\
\text { Value (95\% } \\
\text { Cl) }\end{array}$ & $\begin{array}{l}\text { Accuracy } \\
(95 \% \mathrm{Cl})\end{array}$ \\
\hline $\begin{array}{l}\text { Total } \\
\text { patients }\end{array}$ & $\begin{array}{l}44.83 \\
(34.15- \\
55.87)\end{array}$ & $\begin{array}{l}80.49 \\
(65.13- \\
91.18)\end{array}$ & $\begin{array}{l}67.97 \%( \\
59.15 \text { to } \\
75.94)\end{array}$ & $\begin{array}{l}82.98 \\
(71.51- \\
90.45)\end{array}$ & $\begin{array}{l}40.74 \\
(35.05- \\
46.69)\end{array}$ & $\begin{array}{l}56.25 \\
(47.21- \\
65)\end{array}$ \\
\hline $\begin{array}{l}\text { Patients } \\
\text { with } \\
\text { hypertension }\end{array}$ & $\begin{array}{l}55.36 \\
(41.47- \\
68.66)\end{array}$ & $\begin{array}{l}76.92 \\
(56.35- \\
91.03)\end{array}$ & $\begin{array}{l}68.29 \% \\
(57.08 \text { to } \\
78.13)\end{array}$ & $\begin{array}{l}83.78 \\
(71.14- \\
91.55)\end{array}$ & $\begin{array}{l}44.44 \\
(35.83- \\
53.41)\end{array}$ & $\begin{array}{l}62.20 \\
(50.81- \\
72.68)\end{array}$ \\
\hline $\begin{array}{l}\text { Patients } \\
\text { with diabetic }\end{array}$ & $\begin{array}{l}46 \\
(31.81- \\
60.68)\end{array}$ & $\begin{array}{l}84.21 \\
(60.42- \\
96.62)\end{array}$ & $\begin{array}{l}72.46 \% \\
(60.38 \text { to } \\
82.54)\end{array}$ & $\begin{array}{l}88.46 \\
(72.23- \\
95.76)\end{array}$ & $\begin{array}{l}37.21 \\
(30.05- \\
44.97)\end{array}$ & $\begin{array}{l}56.52 \\
(44.04- \\
68.42)\end{array}$ \\
\hline $\begin{array}{l}\text { Patients } \\
\text { with IHD }\end{array}$ & $\begin{array}{l}69.23 \\
(52.43- \\
82.98)\end{array}$ & $\begin{array}{l}64.71 \\
(38.33- \\
85.79)\end{array}$ & $\begin{array}{l}69.64 \% \\
(55.90 \text { to } \\
81.22)\end{array}$ & $\begin{array}{l}81.82 \\
(69.58- \\
89.85)\end{array}$ & $\begin{array}{l}47.83 \\
(33.75- \\
62.25)\end{array}$ & $\begin{array}{l}67.86 \\
(54.04- \\
79.71)\end{array}$ \\
\hline $\begin{array}{l}\text { Patients } \\
\text { with CVA }\end{array}$ & $\begin{array}{l}80 \\
(56.34- \\
94.27)\end{array}$ & $\begin{array}{l}0(0- \\
70.76)\end{array}$ & $\begin{array}{l}86.96 \% \\
(66.41 \% \text { to } \\
97.22)\end{array}$ & $\begin{array}{l}84.21 \\
(81.07- \\
86.91)\end{array}$ & 0 & $\begin{array}{l}69.57 \\
(47.08- \\
86.79)\end{array}$ \\
\hline
\end{tabular}

\section{Discussion:}

Sepsis is a clinical condition leading to organ dysfunction. It is caused by the host's excessive inflammatory response to infection (13). There is no gold standard nor diagnostic criteria to define the diagnosis or prognosis of sepsis. For easier evaluation in the hospital, the qSOFA score was established to help recognize suspected infections patients who appear to have a poor prognosis(14). Recently, Loading [MathJax]/jax/output/CommonHTML/jax.js $\mathrm{rm}$ the validity of qSOFA in comparison with the qSOFA 
criterion and assess its performance in identifying patients with poor sepsis prognosis and diagnosis(14, 15).

Given the establishment of new criteria, the more comprehensive use of qSOFA for the diagnosis of sepsis, and the different results in the studies around the world, we decided to compare the two criteria of qSOFA and qSOFA in the sepsis diagnosis of patients for timely diagnosis and the determination of an appropriate treatment method in a retrospective descriptive study. The results of the present study can assist the treatment staff to determine an appropriate pattern to increase the treatment efficiency of patients with sepsis and prove effective in reducing false-positive cases.

According to our results, based on SIRS criteria, $68 \%(87 / 128)$ of patients were with a definite diagnosis of sepsis. Also, the positive predictive value of the SIRS criteria for the diagnosis of sepsis was $68 \%$. On the other hand, the SIRS criteria classified $68 \%$ patients as sepsis, of which, 44.8 and $55.2 \%$ had positive and negative qSOFA score, respectively. Therefore, our results showed that $44.8 \%$ of the confirmed patients presented qSOFA score. This means that, in every two sepsis patients, one did not meet the qSOFA criteria.

In this regard, the sensitivity and specificity ratios of qSOFA were $44.83 \%$ and $80.49 \%$, respectively. Also, there was a significant correlation between the qSOFA score and sepsis $(p=0.006)$. However, the SIRS was more sensitive than the qSOFA score for the diagnosis of sepsis.

Rodrigo et al., in a meta-analysis study, found that the SIRS criteria was better than qSOFA criteria for sensitivity of the sepsis diagnosis. Only did one study, among the included ones, reveal that the specificity for the diagnosis of infection comparing the SIRS (84.4\%) with the qSOFA (97.3\%) and establish a better specificity with the qSOFA(15).

In another study of 108 severe sepsis patients in the emergency department, a qSOFA score $\geq 2$ was able to identify only $15.4 \%$ of patients compared with $65.4 \%$ for a SIRS score $\geq 2$ (16).

The lower sensitivity of the qSOFA in the diagnosis of sepsis raises concerns regarding the potential delays in sepsis identification and treatment (15). In the present study, the SIRS criteria were better in the diagnosis of sepsis than the qSOFA.

However, according to the literature, the gold standard for the diagnosis of sepsis is not available, so the physician can rely on the intersection of three groups of clinical and laboratory data, namely: general systemic manifestations, organ dysfunction/failure manifestations, and microbiological documentation $(15,17,18)$.

Recently, the new definition of sepsis is clearly centered on the organ dysfunction, which is why the Sepsis-3 task force designed a new tool, the qSOFA (respiratory rate $>22 / \mathrm{min}$, systolic blood pressure $<$ $100 \mathrm{~mm} \mathrm{Hg}$, altered mentation)(7, 19, 20). 
The findings of this study showed a significant relationship between deaths in sepsis patients and qSOFA score results. The ability of the qSOFA to predict the mortality in sepsis patients with positive SIRS was $61.5 \%$ and significantly efficient in predicting mortality (based on AUC analysis). In addition, the sensitivity and specificity of qSOFA criteria were 71 and $72 \%$ for predicting the sepsis-related mortality.

Thus, our report may contribute to the accumulation of evidence on the potential clinical usefulness of qSOFA in the prediction of mortality. This finding is in line with another recently published large retrospective study $(21,22)$.

In study conducted by Heydar et al., the sensitivity to correctly identify the in-hospital mortality was $95.5 \%$ and $90.1 \%$ for SIRS and qSOFA criteria, respectively (23). Moreover, the specificity for SIRS and qSOFA were $5.6 \%$ and $45.7 \%$, respectively (23).

In the present study, a significant correlation was found between the sepsis patients with hypertension ( $p$ $=0.006)$, diabetic $(p=0.027), I H D(p=0.018)$ and the qSOFA criteria. The results showed different sensitivity and specificity of qSOFA criteria among the confirmed sepsis patients with comorbidity.

Among the patients with comorbidity, the highest amount of sensitivity of positive qSOFA score in the diagnosis of sepsis was among the CVA patients (80 and) followed by IHD (69.2\%), while and the biggest amount of specificity was among patients with diabetes (84.2) and hypertension (76.9\%).

In conclusion, there are no significant differences in site of infection between patients with sepsis. Our findings revealed that the qSOFA score was significantly efficient in predicting mortality. These results may help the clinicians obtain further insight into the usefulness of qSOFA. However, the SIRS is more sensitive than the qSOFA score in predicting of the definite diagnosis of sepsis. Therefore, the qSOFA score may seem to be an invaluable tool for the identification of sepsis patients at the ED.

\section{Limitations}

One of the main limitation of our study was Lack of access to microbiological data about infections.

\section{Abbreviations}

AUC: ROC curve; CVA: cerebrovascular accident; CKD: chronic kidney disease; ED: emergency department; IHD: ischemic heart disease; qSOFA: quick Sepsis-related Organ Failure Assessment; SOFA: The Sequential Organ Failure Assessment; SIRS: systemic inflammatory response syndrome; ICU: intensive care unit

\section{Declarations}

\section{Ethics approval and consent to participate}

Thic ctudv wac cunnnortod hv fuilan I Inivarcity of Medical Science (Grant No:12563). Loading [MathJax]/jax/output/CommonHTML/jax.js 


\section{Consent for publication}

This study was confirmed and permitted by the Ethics Committee of Guilan University of Medical Sciences.

\section{Availability of data and materials}

Not applicable

\section{Competing interests}

The authors declare that they have no conflicts of interest.

\section{Funding}

Not applicable

\section{Authors' contributions}

All authors contributed equally to this manuscript, and approved the final version of manuscripts.

\section{Acknowledgements}

The authors wish to extend their gratitude to Guilan University of Medical Sciences for financial support and sponsorship.

\section{References}

[1]. Sakr Y, Jaschinski U, Wittebole X, Szakmany T, Lipman J, Ñamendys-Silva SA, Martin-Loeches I, Leone M, Lupu MN, Vincent JL. Sepsis in Intensive Care Unit Patients: Worldwide Data From the Intensive Care over Nations Audit. Open Forum Infect Dis 2018; 5:ofy313.

[2] Vincent JL, Jones G, David S, Olariu E, Cadwell KK. Frequency and mortality of septic shock in Europe and North America: a systematic review and meta-analysis. Crit Care 2019; 23:196.

[3] SEDIGH ESH, Motamedifar M, Mansury D, Halaji M, Hashemizadeh Z, ALI MY. Bacterial etiology and antibacterial susceptibility patterns of pediatric bloodstream infections: a two year study from Nemazee Hospital, Shiraz, Iran. J Compr Ped 2016; 7:e29929.

[4] Martín S, Pérez A, Aldecoa C. Sepsis and Immunosenescence in the Elderly Patient: A Review. Front Med (Lausanne) 2017; 4:20.

[5]. Ghassabi F, Hashempour T, Moghadami M, Davarpanah MA, Kalani M, Chatrabnous N, Halaji M, Shahraki HR, Hadi N. Bacterial etiology and antibiotic resistance pattern of septicemia in HIV and non-HIV 
patients admitted to tertiary care hospitals, Shiraz, South of Iran. Cell Mol Biol (Noisy-le-grand) 2017; 63:115-21.

[6] Martins FS, Guedes GG, Santos TM, de Carvalho-Filho MA. Suspected infection in afebrile patients: Are they septic? Medicine (Baltimore) 2017; 96:e6299.

[7] Singer M, Deutschman CS, Seymour CW, Shankar-Hari M, Annane D, Bauer M, Bellomo R, Bernard GR, Chiche JD, Coopersmith CM et al. The Third International Consensus Definitions for Sepsis and Septic Shock (Sepsis-3). Jama 2016; 315:801-10.

[8] Tian H, Zhou J, Weng L, Hu X, Peng J, Wang C, Jiang W, Du X, Xi X, An Y et al. Accuracy of qSOFA for the diagnosis of sepsis-3: a secondary analysis of a population-based cohort study. J Thorac Dis 2019; 11:2034-42.

[9]. Sartelli M, Kluger Y, Ansaloni L, Hardcastle TC, Rello J, Watkins RR, Bassetti M, Giamarellou E, Coccolini F, Abu-Zidan FM et al. Raising concerns about the Sepsis-3 definitions. World J Emerg Surg 2018; $13: 6$.

[10] Seymour CW, Liu VX, Iwashyna TJ, Brunkhorst FM, Rea TD, Scherag A, Rubenfeld G, Kahn JM, Shankar-Hari M, Singer M et al. Assessment of Clinical Criteria for Sepsis: For the Third International Consensus Definitions for Sepsis and Septic Shock (Sepsis-3). Jama 2016; 315:762-74.

[11]. Nakayama I, Izawa J, Mouri H, Kitamura T, Shiotsuka J. Mortality and detailed characteristics of preICU qSOFA-negative patients with suspected sepsis: an observational study. Ann Intensive Care 2018; 8:44.

[12] Jiang J, Yang J, Mei J, Jin Y, Lu Y. Head-to-head comparison of qSOFA and SIRS criteria in predicting the mortality of infected patients in the emergency department: a meta-analysis. Scand J Trauma Resusc Emerg Med 2018; 26:56.

[13] Cao C, Yu M, Chai Y. Pathological alteration and therapeutic implications of sepsis-induced immune cell apoptosis. Cell Death Dis 2019; 10:782.

[14]. Andaluz D, Ferrer R. SIRS, qSOFA, and organ failure for assessing sepsis at the emergency department. J Thorac Dis 2017; 9:1459-62.

[15]. Serafim R, Gomes JA, Salluh J, Póvoa P. A Comparison of the Quick-SOFA and Systemic Inflammatory Response Syndrome Criteria for the Diagnosis of Sepsis and Prediction of Mortality: A Systematic Review and Meta-Analysis. Chest 2018; 153:646-55.

[16] Askim Å, Moser F, Gustad LT, Stene H, Gundersen M, Åsvold BO, Dale J, Bjørnsen LP, Damås JK, Solligård E. Poor performance of quick-SOFA (qSOFA) score in predicting severe sepsis and mortality - a Loading [MathJax]/jax/output/CommonHTML/jax.js 
prospective study of patients admitted with infection to the emergency department. Scand J Trauma Resusc Emerg Med 2017; 25:56.

[17]. Sinto R, Suwarto S, Lie KC, Harimurti K, Widodo D, Pohan HT. Prognostic accuracy of the quick Sequential Organ Failure Assessment (qSOFA)-lactate criteria for mortality in adults with suspected bacterial infection in the emergency department of a hospital with limited resources. Emerg Med J 2020; 37:363-9.

[18] Shahsavarinia K, Moharramzadeh P, Arvanagi RJ, Mahmoodpoor A. qSOFA score for prediction of sepsis outcome in emergency department. Pak J Med Sci 2020; 36:668-72.

[19] Marik PE, Taeb AM. SIRS, qSOFA and new sepsis definition. J Thorac Dis 2017; 9:943-5.

[20] Williams JM, Greenslade JH, McKenzie JV, Chu K, Brown AFT, Lipman J. Systemic Inflammatory Response Syndrome, Quick Sequential Organ Function Assessment, and Organ Dysfunction: Insights From a Prospective Database of ED Patients With Infection. Chest 2017; 151:586-96.

[21]. Finkelsztein EJ, Jones DS, Ma KC, Pabón MA, Delgado T, Nakahira K, Arbo JE, Berlin DA, Schenck EJ, Choi AM et al. Comparison of qSOFA and SIRS for predicting adverse outcomes of patients with suspicion of sepsis outside the intensive care unit. Crit Care 2017; 21:73.

[22]. Churpek MM, Snyder A, Han X, Sokol S, Pettit N, Howell MD, Edelson DP. Quick Sepsis-related Organ Failure Assessment, Systemic Inflammatory Response Syndrome, and Early Warning Scores for Detecting Clinical Deterioration in Infected Patients outside the Intensive Care Unit. Am J Respir Crit Care Med 2017; 195:906-11.

[23]. Haydar S, Spanier M, Weems P, Wood S, Strout T. Comparison of QSOFA score and SIRS criteria as screening mechanisms for emergency department sepsis. Am J Emerg Med 2017; 35:1730-3.

\section{Figures}


ROC Curve

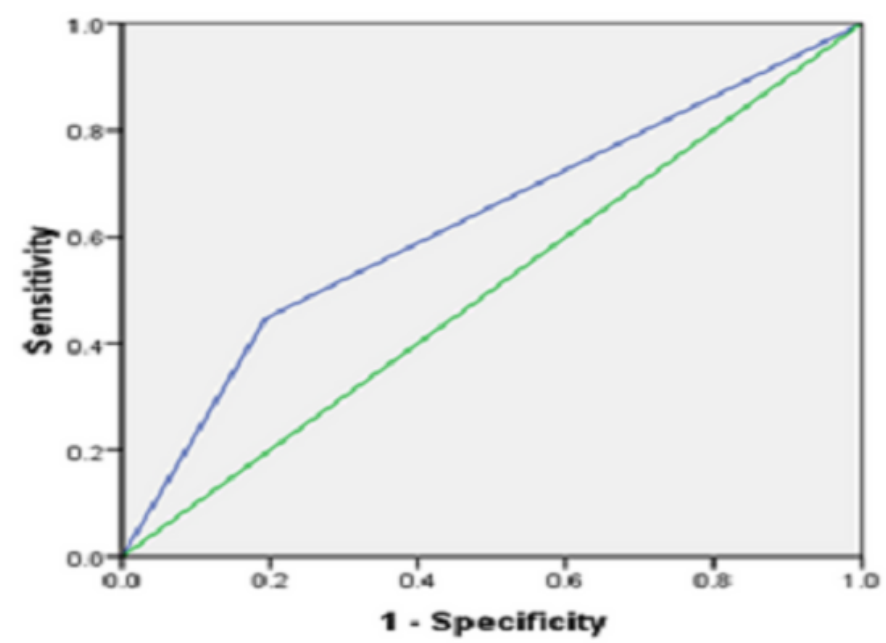

Diagonal segments are produced by ties.
ROC Curve

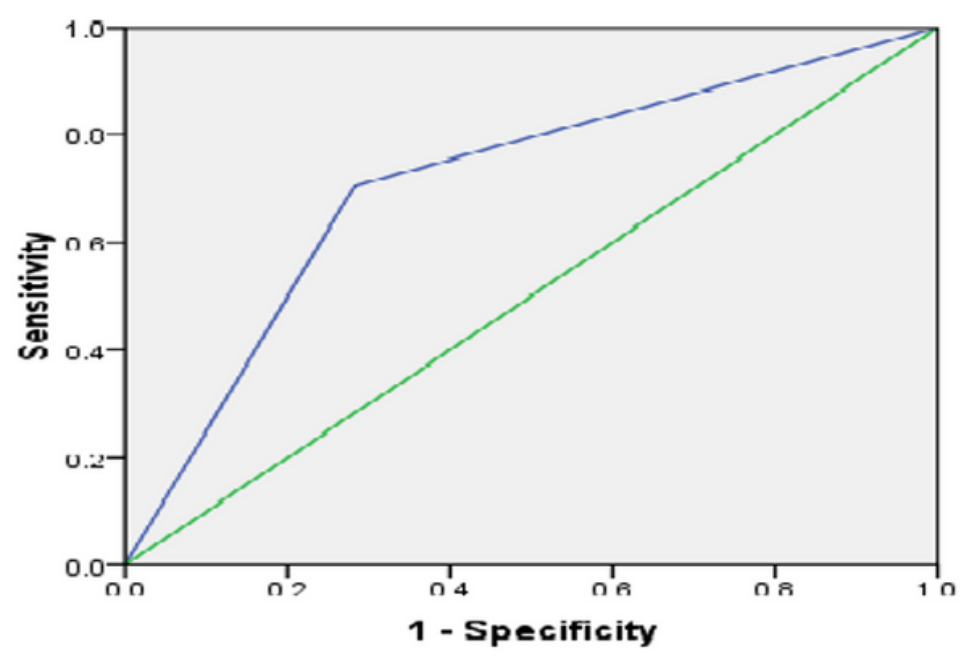

Diagonal segments are produced by ties.

\section{Figure 1}

Prediction of outcome by qSOFA for diagnosis of sepsis and mortality 